\title{
Oscar Wilde y la modernidad
}

\author{
Amparo SerRano de Haro
}

Si en el retrato del crítico del siglo xIx Ruskin representa la conciencia, y Pater la voz, Wilde termina de redondear el cuadro aportando las apariencias, el traje del crítico.

En la literatura critica de Wilde observamos ya los primeros indicios de modernidad presente en los conceptos - que seguidamente pasaremos a estudiar- pero también en el tono. La prosa de Wilde no busca adoctrinar, ni subyugar, todo lo más seducir y con mucha ironía. Ya no estamos en el ámbito público en el que las palabras y oraciones de Ruskin parecen. caer desde lo alto de un púlpito, ni en el intimismo erudito y elitista de Pater. Tanto las conferencias de Wilde en Norteamérica y Canadá, como sus artículos en periódicos, sus ensayos y sus famosos diálogos; “El crítico como artista" presentan una postura más abierta de reflexión crítica.

En 1882, cuando le ofrecieron a Oscar Wilde la posibilidad de dar una serie de conferencias en Estados Unidos y Canadá, no era nadie intelectualmente, gozaba de una cierta fama pero sus intentos como dramaturgo y poeta rabian tenido escaso éxito. En realidad le ofrecen esta oportunidad como parte de una maniobra publicitaria por parte de unos empresarios teatrales para promocionar un espectáculo burlesco, "Patience", que ridiculiza la pose "esteticista" dominante por entonces en los círculos sociales ingleses.

Estas conferencias supusieron para Oscar Wilde un primer esfuerzo en la definición su ideario estético y una oportunidad de entrar en contacto directo con el público.

A primera vista, los textos no son muy valiosos, están construidos a base de "préstamos" de Ruskin, Morris, Pater y Whistler. Es interesante observar cómo Wilde pretende sintetizar todas estas teorias distinguiendo entre arte creativo (Pater, Whistler) y arte decorativo (Ruskin, Morris), siendo el papel de los primeros independiente de la sociedad, 
puesto que su ambición es crear un ideal de pura belleza, mientras los segundos buscan transformar la sociedad con medidas que introduzcan la belleza en la cotidianidad a la vez que transformaban los trabajadores en artistas, es decir, en hombres con capacidad de expresión y de autorealización.

Se percibe también en estas conferencias una determinada progresión que, partiendo de un texto más denso y erudito («The English Renaissance» "), iba hacia la ligereza y los consejos prácticos acerca de cómo decorar ("The Decorative Arts"; "The House Beautiful») en los que insiste en recalcar cómo la belleza no es una cuestión económica: "Cuando os pido que construyáis y decoréis vuestras casas más bellamente no os pido que gastéis mucho dinero, ya que el arte no depende en modo alguno del lujo y la extravagancia" ' a la vez que intentaba demostrar con ejemplos realmente cómicos las funciones pedagógicas y éticas de la susodicha belleza: « ¿Cómo esperas que te digan la verdad si todo lo que les rodea está mintiendo, como el papel del recibidor que pretende ser mármol? Yo he visto papeles de pared responsables de llevar a un chico a una vida de crimen por su sola influencia" ${ }^{3}$.

Algunas de las peculiaridades de Wilde en estas conferencias, residen en su insistencia sobre los aspectos más prácticos de la apreciación del arte. Por ejemplo (además de los citados consejos prácticos sobre decoración -también Ruskin entraba en esos detalles-) su insistencia en la creación de museos como lugar de aprendizaje para el artesano, el trabajador manual, sus observaciones sobre el efecto benéfico de la belleza sobre el ser humano, etc. Wilde empieza todas sus conferencias haciendo una referencia expresa a la forma concreta en que va a tratar el tema del arte y de lo bello por oposición a planteamientos abstractos y filosóficos.

La primera vez que OSCAR WILDE da conferencia, "The English Renaisssance" es el 9 de Enero de 1882 en Nueva York y a pesar de sufrir diversos cambios es la conferencia principal de su "tour".

WILOE, OSCAR. "The house beautiful" (Conferencia incluida en el libro de Kevin O'Brian. Oscar Wilde in Canada. Toronto. personal Library Publishers. 1982). "In asking you to build and decorate your houses more beautifully I do not ask you to spend large sums, as art does not depend in the slightest degree upon extravagance or luxury). Pág. 165. Esta conferencia Wilde la da sólo en aquellas ciudades en que tiene que dar más de una conferencia, es una "conferencia de relleno". Se da la particularidad de que ese mismo título fue el de una obra (muy popular) del critico norteamericano Clarence Cook que se publicó en 1877.

Ibidem. "How can you expect them to tell the truth if everthing about them is telling lies like the paper in the hall declaring itself marbie? Why I have seen wallpaper which must lead a boy brought upp under its influence to a career of crime". O'Brian. Pág. 162. Esta reflexión puede provenir de Stendhal que dijo algo muy similar. 
Es muy posible que haya por parte de Wilde un deseo de amoldarse a los gustos pragmáticos del público, pero también es posible que por aquel entonces Wilde estuviese más cerca de los planteamientos de Ruskin y Morris de lo que cabría suponer. A pesar de lo cual, la influencia de Whistler sobre Wilde se percibe en dos puntos particularmente importantes: la propaganda que hace del arte de Whistler y Albert Moore como exponentes de la mejor pintura del momento; y su desprecio por el crítico.

Para Whistler el crítico no tenía capacidad de juicio sobre la obra del artista, puesto que ignoraba en qué constituye la experiencia creadora, asi lo expondrá años más tarde en su "Ten O'clock Lecture" ${ }^{4}$. Esta conferencia fue un intento por recalcar su superioridad frente a Wilde, quien según él se estaba haciendo famoso a costa de robarle sus ideas. Efectivamente Wilde, al principio, seguía el camino de Whistler, llegando a decir frases como éstas: "Creo que el primer deber de un crítico de arte es callar en todas las ocasiones y sobre todos los temas" ". Lo cual es particularmente llamativo puesto que, posteriormente, será el más acérrimo defensor de la postura contraria. Para Wilde, por entonces, el papel del crítico consistía no en ser el juez del artista, sino en actuar como intermediario entre público y artista: "El verdadero crítico jamás se dirige al artista sino al público (...) el arte que ha llenado las condiciones de la belleza ha llenado todas las condiciones: es al crítico a quien corresponde enseñarle al pueblo a encontrar en la serenidad de ese arte la más alta expresión de sus propias y más tempestuosas pasiones" ${ }^{6}$.

Esta postura de Wilde no duraría mucho y en la serie de artículos que escribe, de 1885 a 1889 , podemos observar cómo se fue alejando personal e ideológicamente de Whistler, aunque sin dejar de apreciar su pintura. Su recensión del "Ten O'clock Lecture» de Whistler manifestaba ya un distanciamiento de su opinión sobre el papel del crítico, al atreverse a mostrar su desacuerdo: “Tampoco acepto la opinión de que sólo un pintor puede juzgar la pintura. Para mí, sólo un artista puede juzgar;

4 Warner, Ehic and Hough, Graham. Ed. Strangeness and Beautv. An Anthology of Aesthetic Criticism 1840-1910. Cambridge University Press. 1983. James McNeill Whistler. "The Ten O'clock Lecture". 1985. "For some time past, the unattached writer has become the middieman in this matter of Art, and his influence, while it has widened the gulf between the people and the painter, has brought about the most complete misunderstanding as to the aim of the picture.

For him a picture is more or less a hieroglyph or symbol of story. Apart from a few technical terms for the display which he finds an occasion, the work is considered absolutely from a literary point of view: indeed, from what other can be consider it?". Pág. 82.

WILDE, OSCAR. "El Renacimiento inglés del arte" (1882) incluido en El Crítico como Artista. Ensayos. Madrid. Espasa-Calpe. 1968. Pág. 156.

lbídem, pág. 157. 
hay gran diferencia (...). Ya que no hay muchas artes, sino tan sólo una; poema, pintura y Paternón, soneto y estatua - todas tienen la misma esencia-y aquél que conoce una, las conoce todas. Pero el poeta es el artista supremo (...) y reina sobre toda la vida y las artes s?. Poco después (en El crítico como artista) la percepción de Wilde sobre este tema se afinaria aún más al caracterizar el elemento crítico como parte constituyente del acto creador.

Tanto en los artículos como en los ensayos que aparecen en 1891 en su obra «Intentions», Wilde no hizo crítica de arte de manera que podamos denominar profesional. Es decir no abordó directamente una pintura para comentarla, aunque sí hacía crítica de literatura y también reseñas. Es patente en él un inusitado interés por ese tipo de actividad, considerada secundaria, como ejercicio intelectual que requiere gran sutileza. Wilde disfrutaba desenmascarando razonamientos aparentes que son en realidad lugares comunes, juicios arrogantes que disimulaban ignorancia, es decir y por decirlo en palabras afines a él, el crítico es el único capaz de desvelar los juegos de máscaras intelectuales. Por eso no es de sorprender el apasionamiento que se refleja en su ensayo «El críticc como artista”.

Se trata de dos textos escritos en forma de diálogo entre los personajes Ernesto y Gilberto; el primero, Ernesto, representa las opiniones de un público ideal, es decir culto y gradualmente convencido por las opiniones del segundo, que sería Gilberto-Wilde.

Como todo aquello excesivamente brillante, una primera lectura del texto puede producir cierta impresión de superficialidad. Un ejercicio dialéctico impecable en el que se trataba de llevar la contraria a lo establecido, a la opinión general sobre un tema. Un análisis más detenido nos demuestra que se trata de criterios sólidos, bien reflexionados presentados bajo un aspecto efectista, teatral y no de frases superficialmente brillantes surgidas a raiz de un ejercicio de esgrima dialéctica.

En este caso la forma del texto contradice su significado, una animación de vaudeville, salpicada de esos brotes de sabiduría epigramática tan típicos de Wilde, para un contenido audaz pero reflexivo.

WILde, Oscar. «Mr. Whistler's Ten O'Clock». Pall Mall Gazette. XLI: 6224. (21 de Febrero 1885) incluido en Richard Ellman. Ed. The Artist as Critic. Critical Writings of Oscar Wilde. 1989. Chicago. The University of Chigago Press. 1989. Nor do I accept the dictum that only a painter is a judge in painting. I say that only an artist is a judge of art; there is a wide difference. (...) For there are not many arts, but one merely; poem, picture, and Partenon, sonnet and statue- all are in the essence the same and he who knows one, knows all. But the poet is the supreme artist (...) and is lord over all life and all arts", pág. 15. 
Finalmente es necesario señalar el formato de obra de teatro que adoptan las reflexiones estéticas de Wilde. Este recurso puede parecer novedoso y hasta moderno (la TV y la radio utilizarán mucho la "escenificación" para transmitir conocimientos culturales), pero hay que recordar que la expresión dialogada tiene ecos platónicos y el mismo Goethe la empleó para desarrollar reflexiones estéticas (por ejemplo en su «Propyläen», 1, 1798: Sobre la verdad y la probabilidad en las obras de arte —un diálogo-).

Para Wilde el elemento principal del crítico es su «temperamento», su sensibilidad. Y en "El crítico como artista" afirmaba esa cualidad por encima de las de justo, racional o sincero ${ }^{8}$. El hombre de temperamento artístico se caracteriza no por lo que "hace" sino por lo que es. Esta creencia va a contracorriente con el positivismo desde el que nuestra época y el siglo $X I X$ han evaluado los méritos de los hombres. El único parangón está en la hagiografia mística, en la que la pura vida contemplativa era mérito suficiente para declarar a alguien santo. También en el mundo antiguo la sabiduría no se manifestaba en la elaboración de sesudos volúmenes sino que era un modo de vivir. Pero volviendo a Wilde, está claro que se trata de un último coletazo del movimiento romántico que promulgaba la estrecha asociación entre vida y arte. Además del papel que el artista jugaba en la "lucha anti-burguesa" se medía en todo tipo de detalles. La elección de un sombrero determinaba una carrera de genio tanto o más que la publicación de un libro.

Esta primacía que Wilde concedía a la sensibilidad, al temperamento, le harán seguir a Pater a la hora de definir la formación del critico (que en Pater se confundía con el amante de todo lo bello). Para Wilde clas verdades del arte no pueden ser enseñadas: sólo son reveladas, reveladas a temperamentos que se han tornado receptivos a todas las bellas impresiones por medio del estudio y de la adoración de las cosas hermosas" ?. Observemos cómo aquí Wilde da un carácter netamente menos "místico" a la revelación, tal y como aparece en Ruskin y Pater, además de vincularlo no al mensaje escondido de Dios en la naturaleza (Ruskin), ni a un momento "sublime" en el que el mundo interno y externo se fusionan en armonía (Pater), sino al "estudio" y a vivir de manera cotidiana en un entorno de "cosas hermosas".

El desarrollo de la personalidad y, por lo tanto, del temperamento es esencial tanto para el artista como para el crítico en la tradición romántica.

WILDE, OSCAR. El Crítico como Artista. Ensayos. págs. 82-83.

Wilde, OsCar. «El renacimiento inglés del arte». El Critico Como Artista. Pág. 163. 
La relación entre biografía y crítica, y biografía y obra de arte fue algo importante para Wilde, y alude directamente a ello en sus textos. Inclusive en nuestra opinión éste es el núcleo argumental verdadero de El retrato de Dorian Gray.

La relación entre crítica y la biografía queda reflejada cuando en «El crítico como artista» Wilde-Gilberto exclama: "Esto es en realidad la crítica más elevada; el documento de nuestra propia alma. Es más fascinante que la historia ya que se refiere simplemente a nosotros mismos. Es más deliciosa que la filosofía, ya que su tema es concreto y no abstracto, real y no vago. Es la única forma civilizada de la autobiografía pues no se refiere a los acontecimientos, sino a los pensamientos de nuestra vida" ${ }^{10}$.

Por otra parte, la vinculación entre biografía y obra en «El retrato de Dorian Gray", queda establecida cuando el pintor Basil Hallward teme que su pintura pueda reflejar los secretos sentimientos que le dominaban al crearlo: «Entonces, ¿por qué no quiere usted exponer su retrato? preguntó Lord Henry. Porque, sin pensarlo, he puesto en él la expresión de toda esa extraña idolatria, artística naturalmente, de la cual nunca le he hablado (...) el mundo podría adivinarla, y no quiero desnudar mi alma frívola ante miradas curiosas. Mi corazón no estará nunca bajo su microscopio" ". Seguidamente el pintor añade "Vivimos en una época en que los hombres no ven el arte más que bajo una forma autobiográfica. Hemos perdido el sentido abstracto de la belleza" ${ }^{2}$.

La aparente contradicción entre ambas posturas no es un juego dialéctico sino que refleja la ambivalencia de su época. Existía en el mundo victoriano una asociación muy fuerte entre obra y autor, de hecho el juicio contra Wilde empezó siendo un juicio sobre sus obras. Wilde, en toda su defensa escrita de "El retrato de Dorian Gray", como en los preliminares de su juicio, repite incansablemente que no hay una obra moral o inmoral sino sólo mal o bien escrita (con Wilde el ideal romántico entre vida-arte empieza a resquebrajarse para dar lugar a una perspectiva más especializada). Sin embargo Wilde tanto como Ruskin y Pater se manifestaban, se expresaban veladamente a través de sus escritos y él mismo fue al martirio por esa asociación.

Wilde fue deudor de dos posturas críticas distintas, la de Pater y la de Whistler. Ruskin de quien habló a menudo elogiosamente, sobre todo en

\footnotetext{
WILDE, Oscar. El Critico como Artista. Madrid. Espasa-Calpe, 1968. Pág. 45. WILDE, OsCAR. El Retrato de Dorian Gray. Barcelona. Ed. Zeus, 1973. Pág. 46. Ibídem, pág. 46.
} 
sus discursos norteamericanos (Ruskin era muy popular en EE.UU. donde ejerció una gran influencia) pertenece a una concepción crítica distinta.

El propio Wilde marca esa diferencia: “Ese amor del arte por el arte, constituye el punto en que nosotros, los pertenecientes a la nueva escuela, nos hemos separado de la enseñanza de Ruskin, separación definitiva, divergencia decisiva./ Fue él quien (...) nos enseñó en Oxford ese entusiasmo hacia la belleza que es el secreto del helenismo y ese anhelo de creación que es el secreto de la vida (...) sin embargo, en su crítica de arte (...) ya no estamos con él, pues la clave de su sistema estético es siempre ética» ${ }^{13}$.

De alguna manera Pater constituye la influencia teórica de lo que debe de ser el crítico; Whistler la influencia práctica del pintor. Whistler le presentó a los impresionistas, le enseñó a valorar un cuadro dejando de lado consideraciones literarias, como el tema, para descubrir otras como el color, las armonias, la intención del artista ... dice por ejemplo Wilde hablando de las virtudes de Wainwrigt como crítico de arte: "Las cualidades que busca en un cuadro son composición, belleza y dignidad de línea, riqueza de color, y poder imaginativo" ${ }^{4}$. Desgraciadamente su ruptura con Whistler le fue alejando del aspecto práctico del arte, a la vez que le indujo como respuesta a demostrar la inferioridad de la pintura frente a la literatura. Podemos decir que "El crítico como artista» es una defensa basada en Pater y contra Whistler.

En el concepto de crítica de Wilde confluyeron, pues, la práctica pictórica de Whistler y el aspecto teórico sentimental de Pater puesto de manifiesto en afirmaciones como ésta: "La forma es el principio de todas las cosas. (...) Si, la forma lo es todo. Es el secreto de la vida. Halla expresión a un dolor y te será caro. Halla expresión a una alegría e intensificarás su éxtasis» ${ }^{15}$. Un formalismo atemperado por la importancia que da a la historia: "Quien desee comprender verdaderamente a Shakespeare debe de comprender las relaciones de Shakespeare con el Renacimiento y con la Reforma, con la época de Isabel y de Jaime ..." ${ }^{16}$. Efectivamente y esto es curioso, a pesar de la importancia que da Wilde al temperamento, este no es algo que se crea sin una formación. En ese

"WILde, Oscar. Ensayos. Articulos. Barcelona. Ediciones Orbis. 1986. Pág. 234.

14 WILDE, Oscar. "Pen. Pencil and Poison". Intentions (1891) incluido en The Artist as Critic. Critical Writings of Oscar Wilde. Ed. R. Ellman (1989). "The qualities he sought for in a picture were composition, beauty and imaginative power". Pág. 327.

1.5 WILDE, Oscaf. El Critico como Artista. Madrid, Espasa Calpe. Pág. 91.

16. Ibidem, pág. 58. 
sentido no sólo hay que relacionar temperamento con personalidad, sino también con ese "cultivarse a si mismo" humanista y que Wilde atribuye como el mejor legado de Goethe ${ }^{17}$.

La influencia de Whistler paralizó algunas de las tendencias subjetivas auto-exploratorias de Pater para ligarlas a la crítica de obras actuales y a una actitud más vital y más moderna.

Pero antes de ir más lejos, es necesario aclarar algo muy importante: Wilde se refiere en numerosas ocasiones a lo que él llama «arte moderno» en términos despectivos; ese arte moderno era la tendencia "naturalista" de Courbet y compañía contra la que a fines de siglo se rebeló el movimiento simbolista, no precisamente lo que desde nuestra perspectiva y conociendo la trayectoria de las vanguardias calificaríamos de arte moderno.

Esta presunta actualidad crítica de Wilde que yo defiendo, se basaria en el desarrollo de estos conceptos: una valoración de la intención de la obra, de lo incompleto, la falta de importancia que concede al tema (en lo que coincide con la postura Formalista) y una marcada alusión positivista a lo que denomina «progreso».

El tema de la «intención» puede provocar malentendidos, porque Wilde lo empleó de formas distintas. Para lo que nos interesa, Wilde decía que "Toda obra imaginativa hermosa tiene conciencia de sí misma y es intencional (...) no hay arte bello sin conciencia de nosotros mismos, y la conciencia de nosotros mismos y el espíritu crítico son una sola y misma cosa". Aquí Wilde está hablando de la capacidad de una obra de creerse a si misma, con independencia de su tema o lo que llamamos superficialmente su estilo. Es decir, de presentar su originalidad y su plena realización desde sus propias leyes, y sus propias intenciones. Este es un audaz pensamiento ya que sería la piedra de toque en la que se va a basar la crítica posterior que se enfrentó a un arte que no entra en unas categorias fijadas de antemano, sino cuya ambición radicará en la creación de su propia categoría. En esta línea ahondó Wilde cuando dice «la dificultad a la que se ve enfrentado quien hace la reseña crítica, es la de mantener algún patrón. Donde no hay estilo debe de ser imposible un patrón» ${ }^{18}$. Este patrón o sistema de referencias internas que tiene la obra es donde

\footnotetext{
17 Ibidem. "El verdadero ideal del hombre es cultivarse a si mismo. GOETHE lo comprendió y la deuda directa que tenemos con Goetre es más grande que la contraida con cualquier otro hombre de la época de los griegos". Pág. 76.

is lbidem, pág. 35.
} 
reside su mayor mérito ${ }^{19}$. La modernidad artística, tal y como nosotros la vemos, es la mayoría de edad de la creación en la que su mérito no se trasladará a categorías ajenas a la obra, sino que está en ella misma. La labor del crítico moderno consiste en encontrar el «patrón» de una obra y observar con respecto a él si sus distintos elementos se encajan. adecuadamente, propiciando su éxito o fracaso.

Al mismo tiempo Wilde decia que «(la verdadera crítica) no se limita (...) a descubrir la verdadera intención del artista y a aceptarla como definitiva. (...) Incluso es todavía más el contemplador quien da a la cosa bella su miriada de sentidos ...". De esta manera el papel de juez supremo que Whistler pretendia adjudicar al artista queda relegado por la importancia del espectador o crítico. Pero Wilde aún va más lejos: "Tenemos que distinguir como cosas distintas la intención del artista y la intención o patrón de la obra, siendo ese concepto el verdaderamente interesante ${ }^{20}$. El reconocimiento de la estructura interna de la obra para fines de enjuiciamiento es algo realmente importante en el pensamiento de Wilde.

El concepto de lo inacabado que vamos a tratar ahora significa una línea divisoria entre la concepción estética romántica y la clasicista. El objetivo final no sería ya la creación de una imagen perfecta, sino la de captar el deseo de expresividad del autor. Sin embargo, el concepto de lo "inacabado" en Wilde resulta mucho más limitado, pues: "El arte se vuelve precisamente completo en belleza gracias a lo incompleto, y por eso no se dirige a la facultad del reconocimiento, ni a la facultad de la razón, sino sólo al sentido estético" "2. Parece producto más de argot de taller impresionista captado a la vera de Whistler que resultado de una reflexión. (Este aspecto de lo incompleto, la diferencia entre esbozo y obra terminada, fueron todos conceptos que se discutieron en el juicio de Whistler).

Otro aspecto artístico muy en boga en relación con la pintura de ese momento, como la de Whistler, el movimiento del arte por el arte y los Impresionistas, es la escasa importancia que tiene el tema. De nuevo Wilde trasladará un elemento del debate artístico para incorporarlo a la crítica: "Para un artista tan creador como el crítico, ¿qué significa el tema?» (...) Con temas de poca o ninguna importancia, tales como los cuadros de la

13 La identificación entre crítico y artista que hace Wilde nos permite aplicar este comentario sobre el crítico al artista. También significa que la labor crítica no consiste en el libre ejercicio de la subjetividad, sino que debe ceñirse a unas directrices (surgidas de la observación empirica y de la formación cultural) generales desde las que enjuiciar la obra.

20 lbídem, pág. 47.

21 Ibídem, pág. 51 
Real Academia de este año ... el verdadero crítico puede (...) producir una obra impecable en punto a belleza y animada de sutileza intelectual ${ }^{22}$.

Wilde habla aqui por experiencia propia, él mismo se había ejercitado en ese tipo de critica ${ }^{23}$. Y esta importancia concedida al tratamiento del cuadro por encima de su tema señala el fín de las jerarquías académicas del siglo XVIII.

La importancia que Wilde daba al concepto de «intención» (por si fuera poco así titula su último volumen de ensayos, Intenciones), servirá de clave para entender tanto lo inacabado, como la escasa importancia del tema. Es decir, la intención del artista se percibe más claramente en una obra inacabada y el tema de una crítica o de un cuadro es menos importante que la intención con la que un artista acomete ese tema.

Igualmente, la idea de progreso está profundamente vinculada al concepto de crítica que Wilde propugnaba. Y por eso mismo este concepto de crítica era ya indicio de la modernidad: «Porque es la facultad crítica quien inventa formas nuevas. La creación tiende a repetirse. Es al instinto crítico a quien debemos cada nueva escuela que surge, cada nuevo molde que el arte halla al alcance de la mano. El mero instinto creador no innova, imita» ${ }^{24}$.

Es decir, que para Wilde el progreso en si ya era algo favorable, siguiendo la consigna de Baudelaire: «il faut être absolument moderne». Y por lo tanto entraba un nuevo requisito en la valoración de las obras que es su modernidad o novedad: "Sus obras no guardan una relación intelectual con su tiempo. No nos aportan elementos nuevos de placer. No sugieren ningún desvio nuevo del pensamiento, de la pasión o de la belleza. (...) Debieran ser abandonadas al olvido que se merecen» ${ }^{25}$.

Finalmente es preciso resaltar un aspecto de la visión de Wilde que resulta curiosamente premonitorio, cuando dice en la segunda parte de su discurso sobre el crítico como artista que el futuro pertenece a la crítica: "Yo mismo me inclino a creer que la creación está condenada. Surge de un impulso demasiado primitivo, demasiado natural. Sea como fuere, es seguro que el material a disposición de la creación disminuye constantemente, en tanto que el material a disposición de la crítica aumenta a diario. Siempre hay nuevas actitudes para el pensamiento y nuevos puntos de vista» ${ }^{26}$.

lbidem, págs. 43 y 44 .

Como son por ejemplo "London Models" (1889), "The blue book» (1889), "To Read or not to Read" (1986), "A cheap edition of a great Man" (1887) en que partiendo de un tema absolutamente trivial logrará un texto bello en su ironia casi poética.

M Wilde, Oscar. El Critico como Artista. Madrid. Espasa Calpe. 1968.

it. lbidem, pág. 36.

Ibídem, pág. 96. 
Contrariamente a Pater (que nunca aludió a ello), en Wilde existió una preocupación por la relación entre arte y sociedad, pues no en vano fue alumno de Ruskin. Es algo á lo que aludió sin desarrollarlo, limitándose a comentar en algunos de sus escritos la relación entre lo hermoso y lo útil, la importancia de vivir rodeado de objetos bellos para una vida armoniosa, que los obreros vivan en un ambiente agradable para que sean capaces de crear objetos bellos y la relación entre capacidad creativa y Humanidad. La asociación entre belleza y bienestar es tan fuerte en Wilde que paraliza cualquier serio intento por plantearse la cuestión social. A pesar de lo cual, en alguna de sus conferencias norteamericanas y más tarde en «The soul of man under socialism" ${ }^{27}$, se lo planteó con consecuencias nefastas, ya que lo que empieza siendo un alegato a favor del socialismo acaba siendo un ensayo sobre los peligros que corre el creador, ser individualista por antonomasia, a manos de la prensa y de la estupidez del público general. Oscar Wilde se desahoga asi de los más duros ataques que recibió de la prensa por su obra "El retrato de Dorian Gray".

El juicio y condena de Oscar Wilde en 1896 marca el final de una actitud artística y crítica: Como dice Richard Aldington "La calle Wardour fue abandonada por Bloomsbury, el esteta se convirtió en el erudito, el amante-de-la-Belleza fue reemplazado por el exhibicionista intelectual»" ${ }^{28}$.

La crítica artística que estos hombres habian realizado basándose en su sensibilidad es sustituida por enfoques más científicos y objetivos.

Esta doble conciencia del crítico, conciencia de la obra y de la reacción de su propia sensibilidad frente a la obra -toda crítica fue a la vez tanto un análisis artístico como el retrato del crítico- desaparece.

Así, cuando Wilde mató a Dorian, es decir, cuando Dorian Gray apuñala su propio retrato porque como dice Wilde: "Es para librarse de su conciencia que le iba siguiendo los pasos año tras año, por lo que destruye el cuadro ${ }^{23}$, puso fín a esta doble actitud de observar y observarse a si mismo observando, decadencia última del sueño estético ... una posible interpretacion simbólica de esta obra polifacética. Ellman.

WILDE, OSCAR. The soul of man under socialism (1891) recogido en The Artist as Critic de $R$.

2 Aldington, Richard. The Religion of Beauiy. Melbourne. London. Toronto. William Heineman Ltb. 1950. Pág. 6.

"WILDE, OSCAR. "It is to get rid of the conscience that dogged his steps from year to year that he destroys the picture". To the Editor of the "Dailey Chronicle". 30 June 1890. Incluido en Artist as Critic. Ed. Ellman. 1982. Pág. 246 
